\title{
The Effectiveness of an Educational Intervention on Fatigue in Hemodialysis Patients: A Randomized Controlled Trial
}

\author{
Salwa A. Mohamed \\ Medical Surgical Nursing Department, Faculty of Nursing, Fayoum University, Egypt
}

\begin{abstract}
:
Background: Fatigue is considered as a major problem in hemodialysis patients and can impair their quality of life. The purpose of this study was to investigate the effectiveness of educational nursing intervention on fatigue in hemodialysis patients.

Materials and Methods: Quasi-experimental research design was conducted in the Hemodialysis Unit at Public Fayoum Hospital. The data were collected from eighteen hemodialysis patients of both sex randomized selected who corresponded to inclusion criteria and divided into two groups: Experimental and control group (40 subjects fulfilling the inclusion criteria assigned to each group). The measures included the form of sociodemographic characteristics, and Piper Fatigue Scale. Patients in the experimental group received early intervention, while patients in the control group received routine hospital care.

Results: The results of the research showed that significant differences in the total mean score of fatigue in the experimental and control groups after participation in the program $(P<0.001)$. Also there are significantly statistically between age, gender, duration of disease and frequency of dialysis and level of fatigue $(p<0.05)$.

Conclusion: Early intervention protocol leads to improve knowledge related to side effect of hemodialysis e.g. fatigue and reduce fatigue in hemodialysis patients. Therefore, use of this non-pharmacologic technique for hemodialysis nurses is suggested.
\end{abstract}

Key words: ESRD, hemodialysis, fatigue, intervention, self-management.

\section{Introduction}

Chronic kidneey diseaase is aworldwide health problem. Chronic kidney disease (CKD) is often unpredictable and patients may not feel ill as the disease progresses to end stage renal disease (ESRD), an illness that affects over 593,000 people in the U.S. ${ }^{[1]}$ Patients in the end-stage renal disease phase have two options in order to stay alive: life-long dialysis (hemodialysis or peritoneal dialysis) or kidney transplantation. Of these options, dialysis is considered the treatment of choice. Patients on hemodialysis account for approximately $92 \%$ of the overall dialysis population ${ }^{[1]}$ and endure a high symptom burden as they may experience troubling symptoms such as fatigue, decreased appetite, trouble concentrating, swelling in their feet and hands, muscle cramps, and itching. ${ }^{[2-4]}$, all of which cause daily distress and negatively affects their quality of life. ${ }^{[5,6]}$

Haemodialysis plays an important role in maintaining renal function. It filters circulating blood through a semipermeable membrane in an apparatus to remove waste products in case of kidney failure and it attempts in replacing kidney function. ${ }^{[7]}$ The kidney works without a break, every day of the year and every hour of the day. Anything less is not ideal from the perspective of the function of removing excess of fluid and toxins from the body. Patients on hemodialysis experienced a range of symptoms, with considerable variation in the frequency of symptoms experienced and in the severity with which the symptoms affected the individuals. Symptoms expression was significantly associated with sleep problems, fatigue and poor physical functioning. There is considerable potential for enhancement of quality of life by minimizing the symptoms experienced. ${ }^{[8,9]}$

Fatigue is one of the most frequent complaints of haemodialysis patients and is associated with impaired health related quality of life. Fatigue is documented as a negative symptom experienced by a large number of patients with end stage renal disease undergoing hemodialysis. Fatigue is a distressing symptom, and the consequences of fatigue can be overwhelming. ${ }^{[8]}$ The person with fatigue need more efforts to perform activities, physical and cognitive, compared with the effort required before the onset of fatigue. Individual have avoidance behaviour, experience a sense of loss and diminished quality of life. ${ }^{[9]}$ Therefore, the various treatment strategies, that is, exercise, psychosocial support, stress management, nutrition, sleep regulation, and restorative therapy must be effective to attenuate fatigue. ${ }^{[10]}$

In ESRD patients, untreated fatigue may highly affect the quality of life and lead to patients' increased dependency on others, weakness, loss of physical and psychological energy, social isolation, and depression. The elements that can affect the level of fatigue include depression, anemia, sleep disorders, and restless leg syndrome ${ }^{[11]}$ Non-medicational interventions such as nutrition therapy, sleep disorder treatment, stress management, sport, Yoga, depression treatment, drug abuse, and acupressure are used to lower hemodialysis patients' fatigue ${ }^{[12]}$ Previous studies include a systematic review on the effect of acupressure medicine on 
hemodialysis patients' signs including fatigue. ${ }^{[13]}$ Ahlberg et al. ${ }^{[14]}$ would counteract the brevity of the stress management interventions to decrease emotional distress and to improve overall quality of life including fatigue. Stress management and psychosocial interventions (e.g. relaxation training, meditation, psycho-education, communication, and social support. Similarly, study of Yuurlknran et al. ${ }^{[15]}$ stated exercise and yoga have also effective measures in improve fatigue and quality of life.

According to this researcher nursing intervention is essential in this area and must take a proactive role in assisting the patient to learn measures that may ease their sensation of fatigue. Teaching should reflect the current experience of the patient with the disease and treatment as well as her understanding of the principles of daily energy expenditure, conservation, and restoration. ${ }^{[16]}$ Previous studies that have addressed intervention focused on three categories: education, exercise, and attention-restoring activities. ${ }^{[17]}$ Johansson et al. $^{[18]}$ emphasize that patients need information about their disease, its treatment and complication for improve quality of life and decrease level of fatigue.

\subsection{Aim of the study}

This study was aimed to evaluate the effectiveness of an educational intervention on fatigue in hemodialysis patients.

\subsection{Operational definitions:}

\subsubsection{Nursing intervention protocol about fatigue in hemodialysis:}

It is instruction that is provided to the patient/family prior to their initial hemodialysis treatment thus enhancing the patient's knowledge about chronic renal disease and hemodialysis, knowledge about rest, nutrition and exercises, knowledge of coping mechanisms and facilitating adaptation.

\subsection{Research hypothesis}

To fulfill the aim of this study the following hypothesis was formulated:

H1.Patients undergoing hemodialysis that will be exposed to the educational nursing intervention protocol about fatigue care will show lower score than those patients who receive the standard nursing instruction on hemodialysis.

H2. There is a significant association between fatigue and selected demographic variables in patients undergoing haemodialysis in the experimental group.

\subsection{Research design}

\section{Material and methods}

Quasi-experimental research design was utilized to conduct this study.

\subsection{Setting of the study}

The study was conducted in Hemodialysis Unit at Public Fayoum Hospital, Ministry of health.

\subsection{Subjects}

A convenience sample of 80 subjects (40 in the experimental and control group) was initially sought for this study. All adult patients were scheduled for hemodialysis. Subjects for this study met the following criteria: a) recently diagnosed with renal failure and requiring hemodialysis at least three months, b) patients had to be sedentary for six months or more c) 18 years or older; d) and able to communicate. Exclusion criteria were acute heart and lung disease; acute infectious diseases; hemoglobin $<10 \mathrm{~g} / \mathrm{dl}$; physical or mental disability preventing the proper performance of the protocol.

\subsection{Tools for data collection}

Three tools were used to collect data pertained to this study, these tools were tested and piloted by the investigator which is:

\subsubsection{Sociodemographic data and medical data sheet.}

This part was developed by the researcher; it aimed to collect personal, social and medical patient data. It included items related to patient's age, sex, level of education, occupation, marital status, type of residence, co-morbidity, duration of disease, family history related to disease, schedule of hemodialysis planed to take, number of attended hours per week for dialysis, and problem (side effect) occur during hemodialysis e.g. fatigue. It also included lab investigations such as, hemoglobin, sodium, potassium, blood urea, and creatinine.

2.4.2. Structured Knowledge Questionnaires Sheet: This sheet was developed to assess patients' knowledge about chronic renal failure; It consists of 40 questions covering the following areas: general information about $\mathrm{CRF}$, general information about Hemodialysis, clinical manifestation, diagnostic evaluation, knowledge about 
nutrition, self -care measures and knowledge about complication. Each right answer got one score. While no answer take zero score. After construction of the tools, they were evaluated by 5 experts from nursing faculty and nephrology for content of validity, relevance, and tested for reliability (by test- retest) on 10 patients for results of (validity and reliability) were excluded from study.

2.4.3. Fatigue assessment (Piper Fatigue Scale (PFS): The PFS adopted by Piper et al. ${ }^{[19]}$ The PFS-B was designed to measure usual patterns of fatigue and any changes experienced during the six months prior to a medical diagnosis or the start of treatment. Fatigue symptoms were measured using a (0-10) numeric scale. The PFS in its current form was composed o f 22 numerically scaled from (0 to 10) items that measured four dimensions o f subjective fatigue, behavioral (6 items), affective (5 items), sensory (5 items), and cognitive/mood (6 items). These 22 items were used to calculate the four-subscale/dimensional. Both a total score (0 to 10) and scores per domain (0 to 10) can be obtain. Higher score indicate fatigue.

\subsection{Human rights and ethical consideration:}

Permission to conduct the study was obtained from the hospitals, authorities of El-Mansoura University. Prior to the initial interview, the researcher introduced yourself to patients who met the inclusion criteria; each potential patient was fully informed with the purpose and nature of the study, and then an informed consent was obtained from participants who accepted to participate in the study. The researcher emphasized that participation in the study is entirely voluntary and withdrawal from the study would not affect the care provided, and confidentiality was assured through coding the data.

\subsection{Data Collection Method:}

- Prior to the data collection, permission was obtained from the concerned hospital authorities for conducting the study.

- Subjects were selected according to the selected criteria. Also written consent was obtained from the subjects and confidentiality was assured

- A pilot study was carried out on $10 \%$ of the subjects (10 patients) undergoing hemodialysis for testing feasibility and applicability of the tools, minimal modifications were made in the data collection tools. Patients included in the pilot study were excluded from the study subjects.

- The researcher started the data collection and implementation of the program from the November 2013 to December 2013.

- The patient assessment sheet was filled by the researcher through personal interview, within 30-40 minutes, the purpose of the study was explained to them and an informed consent to participate in the study was taken.

- Intervention program. Subjects were exposed to the intervention program activities which are 4 consecutive sessions over two weeks. Each session lasted from 30 - 45 minutes. The first two sessions were designed to equip subjects with the necessary basic information related to the chronic renal disease. One session about diet, two sessions about hemodialysis care and session about stress management and physical therapy. Methods and media of teaching used in the training sessions: Lectures, discussions, booklet and demonstration. Pictures, videos and colored booklet.

- The control group received the usual care recommended by the nephrologists' in relation with healthy lifestyle. The experimental group recived the intervention program.

- The post intervention, assessment for fatigue was conducted throughout three phases of assessment: a) immediately post participation of program, and b) three months after intervention for both groups by using the same scale. The evaluation was filled by the researcher for both experimental and control groups within 20-30 minutes to estimate the effect of the intervention programs on reduction fatigue.

\subsection{Statistical analysis}

Data entry and statistical analysis were done using SPSS 15.0 statistical software package. Descriptive statistics were presented as mean and standard deviation were used to characterize subjects in this study. In order to determine if there was a significant difference in the level of fatigue in the control and experimental group of subjects an independent t-test was performed. For categorical variable comparison between groups using chi-square test and a significance level of $\mathrm{p}<0.05$ was set for all statistical procedures.

\section{Results}

Figure 1.Gender distribution of sample reveals that about (55\%) of the experimental group and (50\%) of the control group were female. While $(45 \%)$ of the experimental group and $(50 \%)$ of the control group were male. No significant difference was detected between the two groups $(\mathrm{P}>0.05)$.

Figure 2. The percentage distribution of patients in education level shows that among $(40 \%)$ of the experimental group and $(37 \%)$ of the control group were secondary education, and (30\%) in the experimental group and 
$(35 \%)$ of the control group were illiterate. No significant difference was detected between the two groups $(\mathrm{P}>$ $0.05)$.

Table 1. Age wise distribution of sample reveals that majority $(65 \%)$ in the experimental group and $(75 \%)$ of control group were ranged between 41-55 years of age. While in the age group of more than 56 years of age $(7.5 \%)$ in experimental and (2.5) in control group in particular study. Most of the women in both groups were married $(80 \%)$ and $(65 \%)$, respectively. As regards to employment status $(45 \%$ and $50 \%$ of the experimental and control group, respectively) were housewives. While $(15 \%$ and $20 \%)$ in intervention and control group were worker, respectively. In relation to rural and urban area, it shows that the most $(72.5 \%$ and $75 \%)$ in the experimental and control group are belongs to the urban area. In relation to monthly income, The percentage distribution of patients that shows about (50\% and 45\%) in experimental and control groups belongs to the economic condition between 250 - 500 per month family income, while $25 \%$ and $37.5 \%$ in experimental and control group less 250 monthly income.

Table 2. Describes the distribution of the patients according to parameters of hemodialysis. It shows that (35\%) of patients in the experimental group were history of dialysis ranged between (25-50) months compared to $(40 \%)$ of patients in the control group with no statistically significant difference between both groups ( $\mathrm{p}>0.05)$. Regarding frequency of dialysis, the majority $(85 \%$ and $87.5 \%)$ of the patients in the experimental and control groups were two frequency per weeks, while $(15 \%)$ in the experimental and $(12.5 \%)$ in the control group were three per weeks. There were no statistically significant difference between them $(p>0.05)$.

Figure 3. It shows that the mean score hemoglobin levels in the pre test and post test and follow up. There are no significantly statistically between experimental and control group $(\mathrm{p}>0.05)$

Figure 4. The percentage distribution of sample according CKD etiology reveals that the most prevalent etiology of the disease was chronic glomerulonephritis in (57\%) in the experimental group and $(62.5 \%)$ in the control group and hypertension ( $25 \%$ ) in both groups .

Table 3. It reveals that the difference between the patients in the experimental and control groups regarding to pre, post and follow-up test scores of knowledge. It points that there was no significant statistically differences between the mean scores of knowledge for the study and control groups pre program $(p>0.05)$. While improve of mean scores of total knowledge about CKD for the study and control groups after implementation of the program $(38.98 \pm 4.52$ and $23.76 \pm 4.03$ in post test; $34.68 \pm 4.52$ and $23.98 \pm 3.53$ follow up test, respectively). There was highly significant statistically differences between the mean scores of total knowledge for both groups after implementation (post and follow up) of the program $(\mathrm{p}<0.01)$. This illustrated graphically (Figure 4.)

Table 4. This table points that there was no significant statistically differences between the mean scores on the degree of fatigue for experimental and control groups pre program ( $\mathrm{p}>0.05)$. While mean scores and standard deviation of total fatigue score for the experimental and control groups after and follow up implementation of the program $(4.32 \pm 1.6$ and $6.2 \pm 1.8 ; 5.02 \pm 1.6$ and $6.1 \pm 1.7$ respectively). There was highly significant statistically differences between the mean scores of fatigue for both groups after implementation of the program $(p<0.001$ in post test and $\mathrm{p}<0.01$ in follow up, respectively). These may attributed that a lower score on the post-fatigue test of the study group may have been indicative that the nursing intervention and management affected the level of fatigue. Also figure ( $6 \& 7$ ) showed that there was a significant statistical relation between pre, post and pre and post intervention .

Table 5. Illustrates the correlation between fatigue score and some variables among the experimental group pre, post and follow up program. It shows that statistically significant correlation between age and fatigue $(\mathrm{r}=.172$, $\mathrm{p}=0.05 ; \mathrm{r}=-.115, \mathrm{p}<0.01 ; \mathrm{r}=-.62, \mathrm{p}<0.05)$ pre, post and follow up. Also negative statistically significant correlation between fatigue score and frequency dialysis and $(\mathrm{r}=-.481, \mathrm{p}<0.05)$ post program and also history of dialysis $(\mathrm{r}=-.282, \mathrm{p}=0.05 ; \mathrm{r}=-0.453, \mathrm{p}<0.01)$ post and follow up program, which means that increase number of cycle and history of dialysis leads to increase fatigue. Also statistically significant correlation between fatigue score and female than male gender $(\mathrm{r}=-.262, \mathrm{p}<0.01 ; \mathrm{r}=221, \mathrm{p}=0.05)$. While there was no significant statistically difference between education and material status, income in pre, post and follow up program implementation $(\mathrm{p}>0.05)$. Regarding knowledge score, there are statistically significant correlation between fatigue score and knowledge $\operatorname{score}(r=-0.932, p<0.01 ; r=0.284, p<0.05)$, this means nursing intervention affected the level of fatigue. 


\section{Discussion}

Fatigue is an often debilitating symptom in those with ESRD on hemodialysis. As common and extreme as the symptom is in this population, little evidence is available that describes what the experience of fatigue is like for patients on hemodialysis or how they mitigate its effects. ${ }^{[2]}$ This study aimed to evaluate the effect of early interventions on fatigue of patients under hemodialysis treatment.

The present study revealed that the majority of the patients in the experimental and control group belong to age group of 41-55 years and a minimum of patient in both group belong to age group more than 56 years. This finding is supported by the results achieved by Sabouhi, et al. ${ }^{[21]}$ who found that the subjects' mean age in the present study was over 50 years. Tsay and Chen ${ }^{[22]}$ reported more ESRD prevalence at higher ages. The higher numbers of male subjects in the present study and control group reveal that ESRD under hemodialysis treatment prevalence seems to be more prevalent among men. These findings were similar to the finding of the study conducted by Atlantic health science corporation which found that the majority of patients were male. ${ }^{[23]}$ In addition, Nasiri et al. ${ }^{[2]}$ concluded that The higher number of male subjects of ESRD prevalence seems to be more prevalent among men.

With regard to employment status, results of this study revealed that more than two fifths of the experimental and half of subjects in control group were housewife and a minimum of patients in both group were worker . This result supported by the work of Williams et al. ${ }^{[25]}$ who concluded that most of the subjects were retired or jobless in the present study. Studies show that the rate of joblessness is high among hemodialysis patients. In relation to educational level, approximately two third of the experimental and control groups have levels of education (secondary education), while above one third were illiterate, which in contrast with the findings of rebollo and Ortega ${ }^{[26]}$

In the current study, the most of participants in both group reported that the most frequent cause of CKD was chronic glomerulonephritis, followed by hypertension which is consistent with the finding of the study done Henrique et al. ${ }^{[27]}$ Also inconsistent with the result of the present study by Tsay ${ }^{[28]}$ who found that diabetes and hypertension are the major etiologies for ESRD.

Our study shows that nearly two third of experimental and control belong to history of disease 25-50 months. This finding inconsistent with the finding of Babamohammadi et al. ${ }^{[29]}$ who found that average duration of treatment with hemodialysis was $(27.1 \pm 24.2)$ months for case and $(19.38 \pm 25.75)$ months for control group. As regard frequency of dialysis per week, the higher number of subjects in the present study reveals that that ESRD under hemodialysis seems to be prevalent through two dialysis frequency. These study in line with the study of Aba El-Alaa ${ }^{[30]}$ who revealed that the majority of sample in experimental and control group two frequency. In consistent with these findings study by Joshwa et al. ${ }^{[31]}$ found the majority of numbers of cycle were three per weeks. Also present study shows that there are no statistically significant difference between pre, post test and follow up. These study in line with Gil et al. ${ }^{[32]}$ Found that hemoglobin $(\mathrm{g} / \mathrm{dL})$ levels did not differ between period A and period B1 mean score $(10.6 \pm 1.2,10.7 \pm 1.4, \mathrm{p}=0.767)$.

Our study revealed that patients gained higher scores of ESRD knowledge after participation in the early intervention program in the experimental group post and follow up program than control group. This result consistent with the findings of Babamohammadi ${ }^{[29]}$ who reported The results of the research showed that after the home-care program, weight gain, nausea, vomiting, headache, bone pain, weakness and fatigue and itching decreased and general condition and levels of BUN, creatinine, potassium and phosphorus of the blood improved in cases compared to the controls $(P<0.05)$.

The results of the present study revealed that there was a statistical significance difference between the two groups in relation to fatigue severity in post program and follow-up after two month $(p<0.001)$. This attributed that patients received education about diet, physical activity, and social support gained lower scores of fatigue after participation in the intervention program in the experimental group. This result consistent with the findings of Horigan et al. ${ }^{[19]}$ reported demonstrate self-management techniques for patients on hemodialysis use to mitigate fatigue. In the same line, Mohamed ${ }^{[33]}$ who found that a decrease in fatigue severity in the study group with a highly statistical significance difference between the study group, who followed the nursing management program as progressive muscle relaxation technique, patient education about diet, life style modification than the control group.

Página ${ }^{[34]}$ recommended that lifestyle changes, such as exercising more, relieving stress, and eating a healthy, well-balanced diet can help ease fatigue Also, these findings are in agreement with the results of Gaston-Johansson et al..$^{[35]}$ who reported that Dood ${ }^{[36]}$ reported similar findings that education of fatigue management and adequate information regarding self-help measures were valuable in helping subjects deal with the side effects of chemotherapy. Dood's research indicated that information was not enough to influence fatigue in subjects receiving chemotherapy. ${ }^{[36]}$

The results of the present study revealed that patients gained higher scores of ESRD knowledge after participation in the early intervention program in the experimental group post and follow up than control group. This result consistent with the findings of Babamohammadi ${ }^{[29]}$ who reported The results of the research showed 
that after the home-care program, weight gain, nausea, vomiting, headache, bone pain, weakness and fatigue and itching decreased and general condition and levels of BUN, creatinine, potassium and phosphorus of the blood improved in cases compared to the controls $(P<0.05)$.

The results of the current study revealed that there was a positive correlation between patient's fatigue and patient's age post program and follow up. This means that young age tend to have less fatigue level post program and at follow up. These findings are in agreement with the results by Nahamin et al. ${ }^{[37]}$ who found that 52-43 age group had the highest fatigue. These findings are also in agreement with Schneider ${ }^{[38]}$ who reported that with increasing age of dialysis patients, increases fatigue. In this study, there are statistically significant correlation between fatigue score and female than male post program and follow up. In the same line, Transplant ${ }^{[39]}$ reported that most studies, a significant increase of fatigue in hemodialyzed women than men. In addition, plenty of literature exits on greater fatigue among women. ${ }^{[40,41]}$

Also, the results of the present study showed that there was a positive correlation between knowledge of intervention and patient's fatigue post and after three month. These supported by the study of Shah ${ }^{[42]}$ who indicated that quality of life of CRD patients undergoing hemodialysis was influenced by their level of Knowledge. Longman et al. ${ }^{[43]}$ supports these findings, suggesting, nursing needs to clinically individualize nursing interventions for each subject in order to impact the degree of fatigue that results from chemotherapy.

Results of this study showed that there was no statistically significant correlation between marital status, income, and education levels. This result consistent with Nazemian ${ }^{[44]}$ who reported that he results of some studies, indicated fatigue was a significant difference between married and non-married does not show.

\section{Conclusion and recommendations:}

Findings of the present study revealed that indicated that the application of early intervention in ESRD patients undergoing hemodialysis seems effective in increasing hemodialysis and self care measure and also associated with improvement in fatigue and physical capacity.

Based on the results of the present study, the following recommendations are suggested:

- Hemodialysis nurses who deal with patients must be taught that timely follow-up and evaluations of fatigue is essential to the care of patients

- Designing and Developed illustrated booklet about interventions that can be tailored to meet individual needs should be available and distributed for each patient admitted to hemodialysis unit.

- Further research is needed to study associated factors with fatigue in the hemodialysis population.

- Replication of this study on a larger sample and in different hospital settings with increasing the duration of treatment is suggested for generalization of results.

\section{Limitations of the study:}

- The research findings were limited and cannot be generalized because of the small sample size and it was selected from one geographical area in Egypt.

- The scope of the study was also limited as it was restricted to those patients who voluntarily agreed to participant.

\section{Acknowledgement}

I express my gratitude and thanks towards all who have directly or indirectly helped me to complete this study and their support in each major step of the study.

\section{References}

[1]. United States Renal Data System.(2012). United States Renal Data System 2012 annual data report: Atlas of chronic kidney disease and end-stage renal disease in the United States. Bethesda, MD: National Institutes of Health, National Institute of Diabetes and Digestive and Kidney Diseases.

[2]. Almeras C, Argiles A.(2009). The general picture of uremia. Seminars in Dialysis. 2009;22(4):329-333.

[3]. Murtagh FE, Addington-Hall J, Higginson IJ.(2007). The prevalence of symptoms in end-stage renal disease: A systematic review. Advances in Chronic Kidney Diseases.;14(1):82-99.

[4]. Yong DS, Kwok AO, Wong DM, Suen MH, Chen WT, Tse DM.(2009). Symptom burden and quality of life in end-stage renal disease: A study of 179 patients on dialysis and palliative care. Palliative Medicine.;23(2):111-119.

[5]. Jablonski A.(2007). The multidimensional characteristics of symptoms reported by patients on hemodialysis. Nephrology Nursing Journal.;34(1):29-37. quiz 38.

[6]. Weisbord SD, Fried LF, Arnold RM, Fine MJ, Levenson DJ, Peterson RA, et al. (2005).Prevalence, severity, and importance of physical and emotional symptoms in chronic hemodialysis patients. Journal of the American Society of Nephrology.; 16(8):24872494 .

[7]. Alexander M. Global dialysis empowering dialysis users and caregivers. Available from: http://www.empowring//dialysis@/com.html. Assessed October 19, 2012.

[8]. Liu HE.(2006). Fatigue and associated factors in hemodialysis patients in Taiwan. Res Nurs Health; 29:40 - 50.

[9]. Sakhuja V, Sud K.(2003). End-stage renal disease in India and Pakistan: Burden of disease and management issues. Kidney Int;63(Suppl 83):S115-8. 
[10]. Mustian, KM ,Morrow G R, Carroll J K., Flgueroa-Moseley C D, Jean-Pierre P. ,and Williams G C. (2007). "Integrative nonpharmacologic behavioral interventions for the management of cancer-related fatigue," Oncologist, vol. 12, no. 1, supplement 1, pp. 52-67,. View at Publisher · View at Google Scholar · View at Scopus

[11]. Kaba E, Bellou P, Iordanou P, Andrea S, Kyritsi E, Gerogianni G.(2007). Problems experienced by haemodialysis patients in Greece. Br J Nurs; $16: 868-72$.

[12]. Jhamb M, Weisbord SD, Steel JL, Unruh M.(2008). Fatigue in patients receiving maintenance dialysis: A review of definitions, measures, and contributing factors. Am J Kidney Dis;52:353-65.

[13]. Tsay SL.(2004). Acupressure and fatigue in patients with end-stage renal disease-a randomized controlled trial. Int J Nurs Stud;41:99-106.

[14]. Ahlberg K, Ekman T, Gaston-Johansson F.(2005). The experience of fatigue, other symptoms, and global quality of life during radiotherapy for uterine cancer. International Journal of Nursing Studies. 2005;42:377-386.

[15]. Yurlkuran M.,Alp A.,YurtkuranM.,Dilek,K.,(2007). Amodified yoga- based exercise program in hemodialysispatients: randomized controlled study. Complement Ther. Med,15(3):164-171.

[16]. Skalla, Kj A, \& Laçasse, C. (1992). Patient education for fatigue. Oncology Nursing Forum. 19. 1537-1541 Mock, V., Hassey Dow, K., Meares, C.J., Grimm, PM., Dienemann, J-A.

[17]. Clark, PM . \& Laçasse, C., (1998). Cancer-related clinical practice issues. Clinical Journal o f Oncology Nursing. 2(2): $45-53$.

[18]. Johansen KL, Painter PL, Kent-Braun JA, et al(2001).Validation of questionnaires to estimate physical activity and functioning in end-stag renal disease. Kidney Int .;59:1121-1127

[19]. Piper, B f., Lindsey, A_M., Dodd, M.J., Ferketich, S., Paul, S.M., \& Weller, S. (1989). The development o f an instrument to measure the subjective dimension of fatigue. In Funk, S.G., Tomquist, E.M., Champagne, M.T., Archer Copp, L., \& Wiese, R.A. (Eds.), Kev aspects of comfort: Management of pain, fatigue, and nausea (pp. 199-208). New York: Springer Publishing Company.

[20]. Horigan EA., Schneider M S., Docherty S., and Barroso J.(2013). The Experience and Self-Management of Fatigue in Hemodialysis Patients. Nephrol Nurs J. ,40(2): 113-123.

[21]. Sabouhi F., Kalani L., Valiani M, MortazaviM., BemanianM.(2013). Effect of acupressure on fatigue in patients on hemodialysis. Iranian Journal of Nursing and Midwifery Research; 18 (6).

[22]. Tsay SL, Chen M. (2003).Acupressure and quality of sleep in patients with end-stage renal disease - A randomized controlled trial. Int J Nurs Stu;40:1-7.

[23]. Varuglese S., Jacob GT., Alexander S., Deborah MN, Nithya N., Ahmed I.,Tamalarasi V, Jacob CK.(2007). Pretertiary hospital care of patients with chronic kidney disease in indian. Indian J.Med Res.126:28-33.

[24]. Nasiri E, Raei M, Vatani J, Kazemi R.(2011). Effect of acupressure on quality of sleep in hemodialysis patients. J Med Sci;11:23640 .

[25]. Williams AG, Crane P, Kring D.(2007). Fatigue in African American women on hemodialysis. Nephrol Nurs J;34:610-7, 644.

[26]. Rebollo R., Ortega E. (2002). New trends on health related quality of life assessment in end stage renal disease patients.Inturol Nephrol.33:195-202.

[27]. Henrique DM, Reboredo Mde M, Chaoubah A, Paula RB.( 2010). Aerobic exercise improves physical capacity in patients under chronic hemodialysis. 94(6):823-8

[28]. Tsay SL.(2004). Acupressure and fatigue in patients with end-stage renal disease-a randomized controlled trial. Int J Nurs Stud ;41:99-106. Medical Journal; 53(1): 1:5

[29]. Babamohammadi H. and Khalili H.( 2006 ).Effect of a confined program of home- care on the health status of patients receiving hemodialysis. Acta Medica Iranica, 44(1) :28-32.

[30]. Abd El-Aal, A.E.S.(1996).Design a health teaching module for patients with chronic renal failure undergoing hemodialysis :an application of orm self - care. Unpublished Doctoral Thesis. Faculty of Nursing, Alexandria University

[31]. Joshwa B, Khakha DC, Mahajan S. (2012).Fatigue and depression and sleep problems among hemodialysis patients in a tertiary care center. Saudi J Kidney Dis Transpl. ;23(4):729-35.

[32]. Gil,H.W., Bang,K. Lee,Y.S Han, G.B., Kim,K.J., Kim,O.Y., Song,C.H., Kwon,J.Y. and Kim,S.Y. (2014). Efficacy of Hemocontrol Biofeedback System in Intradialytic Hypotension-Prone Hemodialysis Patients. J Korean Med Sci 2014; 29: 805-810

[33]. Mahmoud F. (2002): Breast cancer (MD) Advanced and traditional Imaging Modalities. Ain Shams Medical Journal; 53(1): 1:5

[34]. Página, L. (2012). Fatigue. http://www.breastcancer .org/treatment/ side_effects/ Fatigue. Retrieved at: 20/09/ 2012. 66. Pender, N., Murdaugh, C.

[35]. Gaston-Johansson, F., Fall-Dickson, J.Nada, J., Ohly, K., Krumm, S. \& Kennedy, M. (2000). The effectiveness of comprehensive coping strategy program on clinical outcomes for breast cancer. autologous bone marrow transplantation. Cancer Nursing; 23(4): 277-85.

[36]. Mock, V., Hassey Dow, K., Meares, C.J., Grimm, PM., Dienemann, J-A., Haisfield-Wblfe, M.E., Quitasol, W., Mitchell, S., Chakravarthy, A., \& Gage, I. (1997). Effects of exercise on fatigue, physical functioning, and emotional distress during radiation therapy for breast cancer. Oncology Nursing Forum. 24

[37]. Nahamin M., Hasankhani H., Ghaderi F., Lakdizaji S.(2013). Fatigue and demographic factors influencing on it in dialyzed patients. Intl. Res. J. Appl. Basic. Sci. Vol., 4 (11), 3328-3332.

[38]. Schneider R. (2003). Fatigue among caregivers of chronic renal failure patients: A principal components analysis. Nephrol Nurs J, 30, 629-44.

[39]. -Transplant M.M.D. (2009). Fatigue in people undergoing hemodialysis. 38, 216.

[40]. Loge JH, Ekeberg Ø, Kaasa S. Fatigue in the general Norwergian population: nomative data and associations. J Psychosom Res. 1998;45(1):53-65.

[41]. Manisha,J., Steven,D., Jennifer,L., Steel \& Mark,U. (2008). Fatigue in patients receiving maintenance dialysis. American Journal of Kidney Disease, 52:353-65.

[42]. Shah S.(2011).A study to assess the knowledge regarding self care measures and quality of life among patients with chronic renal failure undergoing hemodialysis. Master thesis, K.L.E University India.

[43]. Longman, A.J., Braden, C.J., \& Mishel, MLH (1997). Pattern o f association over time o f side-effects burden, self-help, and selfcare in women with breast cancer. Oncology Nursing Forum. 2 .1555-1560.

[44]. Nazemian F. G F., Fotokian Z. Poorgaaznatein T. (2006). Stressor and coping strategies with stress in hemodialysis patients. Med J. Mashhad Univ Sci., 49-93, 293-8. 
Results :

Figure 1.Precentage distribution of sunbjects according to gender

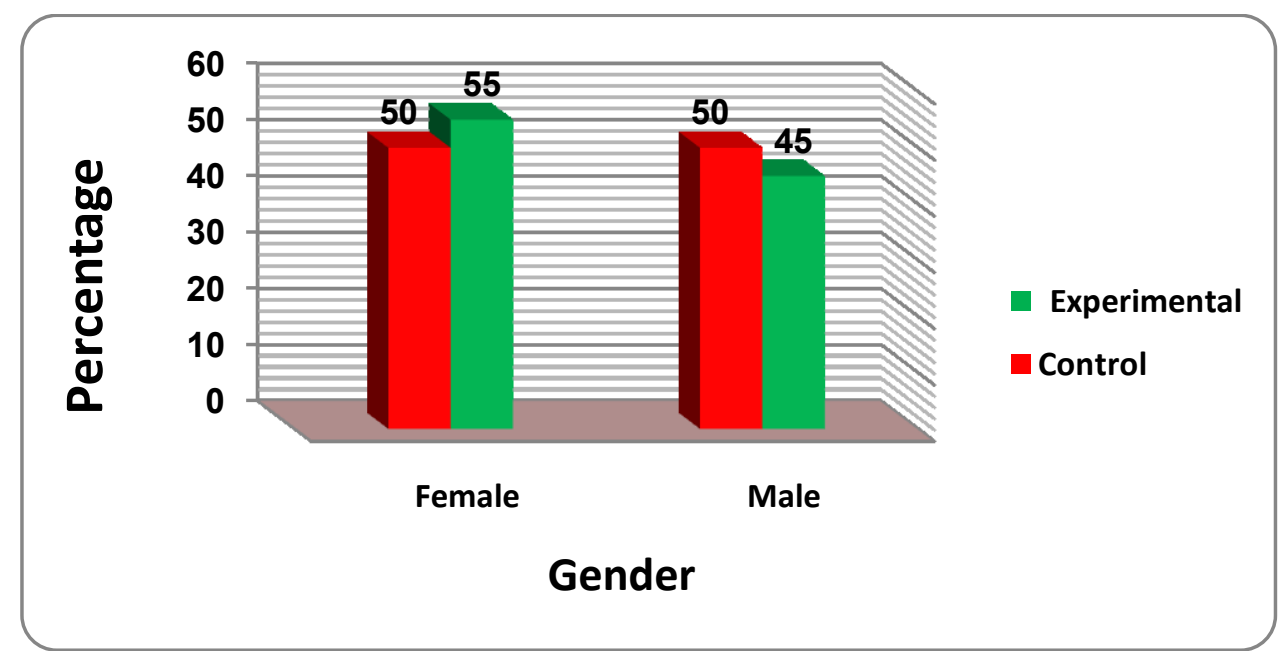

Fig. 2 Distribution of study groups according education status
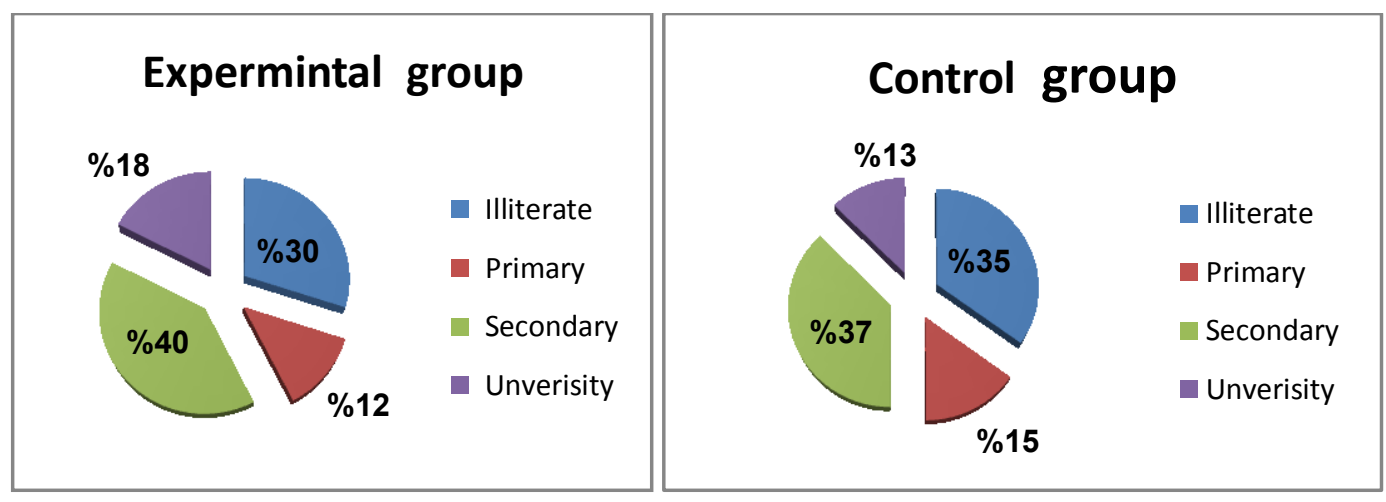

Table.1 Sociodemographic characteristics of patients in the experimental and control Groups $(\mathbf{N}=\mathbf{8 0})$

\begin{tabular}{|c|c|c|c|c|c|c|c|}
\hline \multirow{2}{*}{\multicolumn{2}{|c|}{ Characteristics }} & \multicolumn{2}{|c|}{ Experimental group } & \multicolumn{2}{|c|}{ Control group } & \multirow[t]{2}{*}{$\mathrm{X} 2$} & \multirow[t]{2}{*}{$\mathrm{P}$-value } \\
\hline & & $\mathrm{N}$ & $\%$ & $\mathrm{~N}$ & $\%$ & & \\
\hline \multicolumn{8}{|c|}{ Age: } \\
\hline & $<25 \quad \mathrm{Ys}$ & 3 & 7.5 & 4 & 10 & \multirow{4}{*}{4.21} & \multirow{4}{*}{$\mathrm{P}>0.05$} \\
\hline & $25-40 \mathrm{Ys}$ & 8 & 20 & 5 & 12.5 & & \\
\hline & $41-55 \mathrm{Ys}$ & 26 & 56 & 30 & 75 & & \\
\hline & $>56 \mathrm{Ys}$ & 3 & 7.5 & 1 & 2,5 & & \\
\hline \multicolumn{8}{|c|}{ Marital status: } \\
\hline & Married & 32 & 80 & 26 & 65 & \multirow{3}{*}{0.96} & \multirow{3}{*}{$\mathrm{P}>0.05$} \\
\hline & Single & 1 & 2.5 & 6 & 15 & & \\
\hline & Widow/divorce & 7 & 17.5 & 8 & 20 & & \\
\hline \multicolumn{8}{|c|}{ Employment Status: } \\
\hline & Worker & 6 & 15 & 8 & 20 & \multirow{3}{*}{3.12} & \multirow{3}{*}{$\mathrm{P}>0.05$} \\
\hline & Housekeeping & 18 & 45 & 20 & 50 & & \\
\hline & Retired/student & 16 & 40 & 12 & 30 & & \\
\hline \multicolumn{8}{|c|}{ Residence : } \\
\hline & Rural & 29 & 72.5 & 30 & 75 & \multirow[t]{2}{*}{0.89} & \multirow[t]{2}{*}{$\mathrm{P}>0.05$} \\
\hline$\bullet$ & Urban & 11 & 27.5 & 10 & 25 & & \\
\hline \multicolumn{8}{|c|}{ Monthly Income: } \\
\hline$\bullet$ & $<250$ & 10 & 25 & 15 & 37.5 & \multirow{3}{*}{2.78} & \multirow{3}{*}{$\mathrm{P}>0.05$} \\
\hline & $250-500$ & 20 & 50 & 18 & 45 & & \\
\hline - & $>500$ & 10 & 25 & 7 & 17.5 & & \\
\hline
\end{tabular}


Table.2 Distribution of the studied groups according to clinical parameters

\begin{tabular}{|c|c|c|c|c|c|c|c|}
\hline & \multirow[t]{2}{*}{ Items } & \multicolumn{2}{|c|}{ Experimental group } & \multicolumn{2}{|c|}{ Control group } & \multirow[t]{2}{*}{$\mathrm{X} 2$} & \multirow[t]{2}{*}{$\mathrm{P}$-value } \\
\hline & & $\mathrm{N}$ & $\%$ & $\mathrm{~N}$ & $\%$ & & \\
\hline \multicolumn{8}{|c|}{ History of dialysis (months): } \\
\hline$\bullet$ & $<25$ & 10 & 25 & 8 & 20 & \multirow{4}{*}{1.65} & \multirow{4}{*}{$\mathrm{P}>0.05$} \\
\hline$\bullet$ & $25-50$ & 14 & 35 & 16 & 40 & & \\
\hline$\bullet$ & $50-57$ & 10 & 25 & 12 & 30 & & \\
\hline$\bullet$ & $>57$ & 6 & 15 & 4 & 10 & & \\
\hline \multicolumn{8}{|c|}{ Frequency of dialysis (Weeks): } \\
\hline$\bullet$ & 1 & 0 & 0 & 0 & 0 & \multirow{3}{*}{0.93} & \multirow{3}{*}{$\mathrm{P}>0.05$} \\
\hline$\bullet$ & 2 & 34 & 85 & 35 & 87.5 & & \\
\hline$\bullet$ & 3 & 6 & 15 & 5 & 12.5 & & \\
\hline
\end{tabular}

Figure 3.Mean score of subjects related to CKD hemoglobin levels

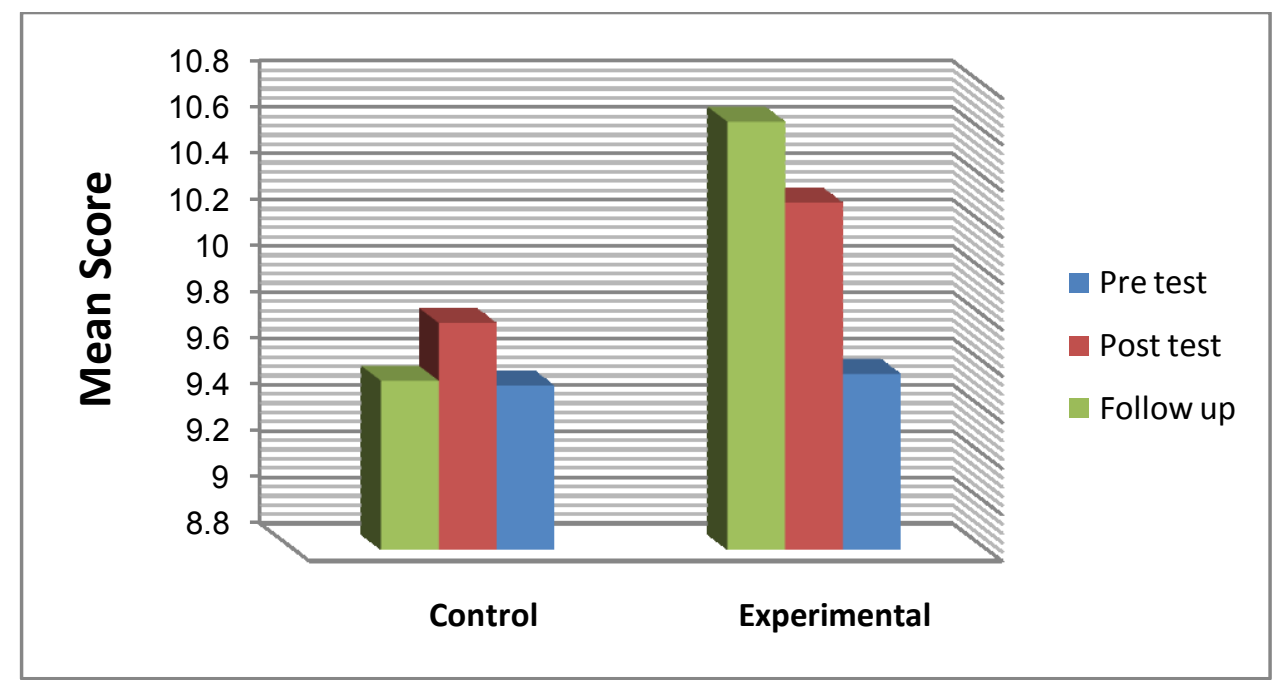

Figure 4.Precentage distribution of subjects according to CKD biology

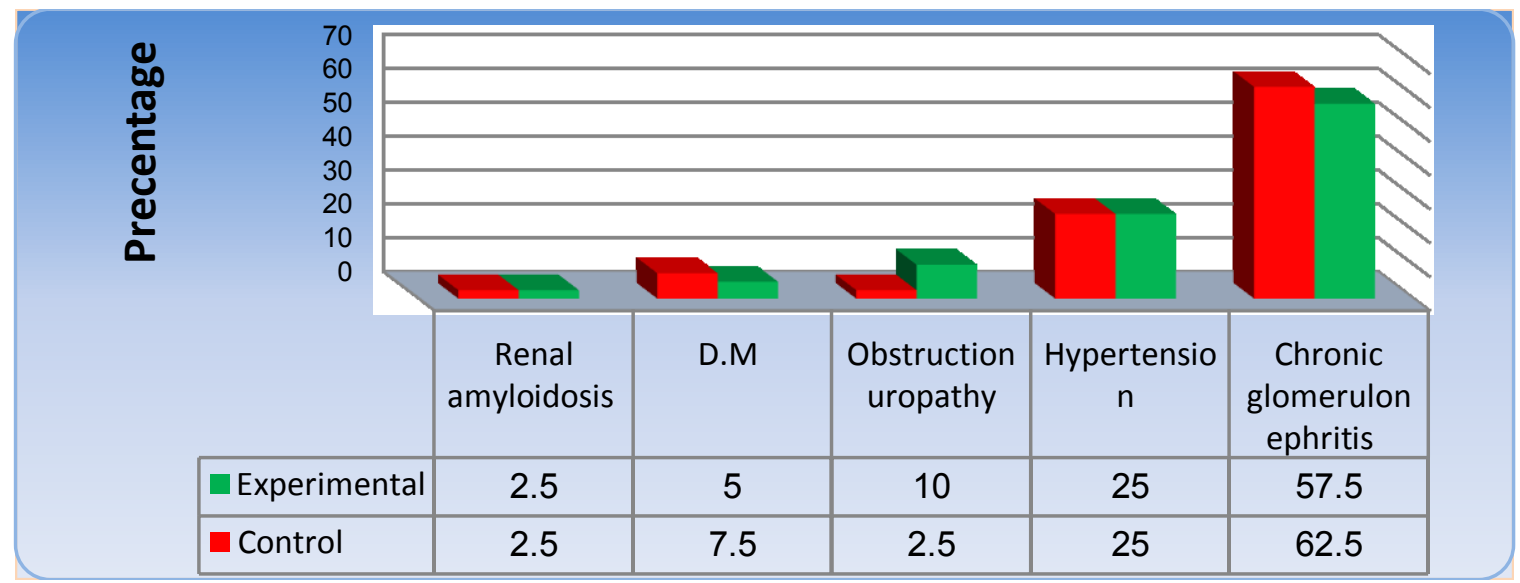

Table 3.Frequency and percentage distribution of knowledge score of subjects in the intervention group

\begin{tabular}{|c|c|c|c|c|}
\hline Knowledge score & $\begin{array}{l}\text { Experimental G. } \\
(\mathrm{n}=40)\end{array}$ & $\begin{array}{l}\text { Control G. } \\
(\mathrm{n}=40)\end{array}$ & t-test & $\mathrm{P}$-value \\
\hline & Mean \pm SD & Mean \pm SD & & \\
\hline Pre intervention & $20.95 \pm 4.13$ & $21.03 \pm 3.57$ & 4.40 & $\mathrm{P}>0.05$ \\
\hline Post intervention & $38.98 \pm 5.6$ & $23.76 \pm 4.03$ & 6.6 & $\mathrm{P}<0.001 *$ \\
\hline Follow up & $34.68 \pm 4.52$ & $23.98 \pm 3.53$ & 4.89 & $\mathrm{P}<0.001$ \\
\hline Pre-post intervention & $\mathrm{P}<0.001 * *$ & $0.653(\mathrm{NS})$ & & \\
\hline Pre-follow intervention & $\mathrm{P}<0.01 *$ & $0.730(\mathrm{NS})$ & & \\
\hline
\end{tabular}


Figure 5. Percentage distribution of knowledge scale

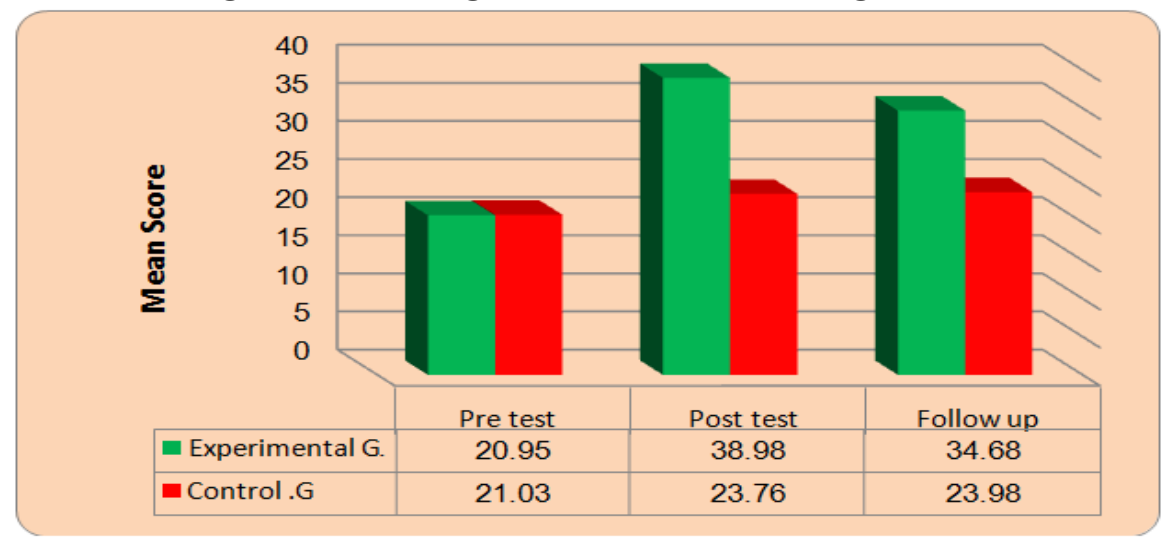

Table. 4 Comparison of piper fatigue dimensions pre, post, and follow up implementation of intervention in both groups

\begin{tabular}{|c|c|c|c|c|}
\hline \multirow[t]{2}{*}{ Piper Fatigue Scale } & Experimental G. & Control G. & \multirow[t]{2}{*}{ Paired - $t$} & \multirow[t]{2}{*}{$\mathrm{P}$-value } \\
\hline & Mean \pm SD & Mean \pm SD & & \\
\hline Pre intervention & $6.3 \pm 2.03$ & $6.6 \pm 2.15$ & 1.39 & 0.43 \\
\hline Post intervention & $4.34 \pm 1.6$ & $6.2 \pm 1.9$ & 8.01 & $<0.001$ \\
\hline Follow up & $5.02 \pm 1.9$ & $6.1 \pm 1.86$ & 7.50 & 0.01 \\
\hline
\end{tabular}

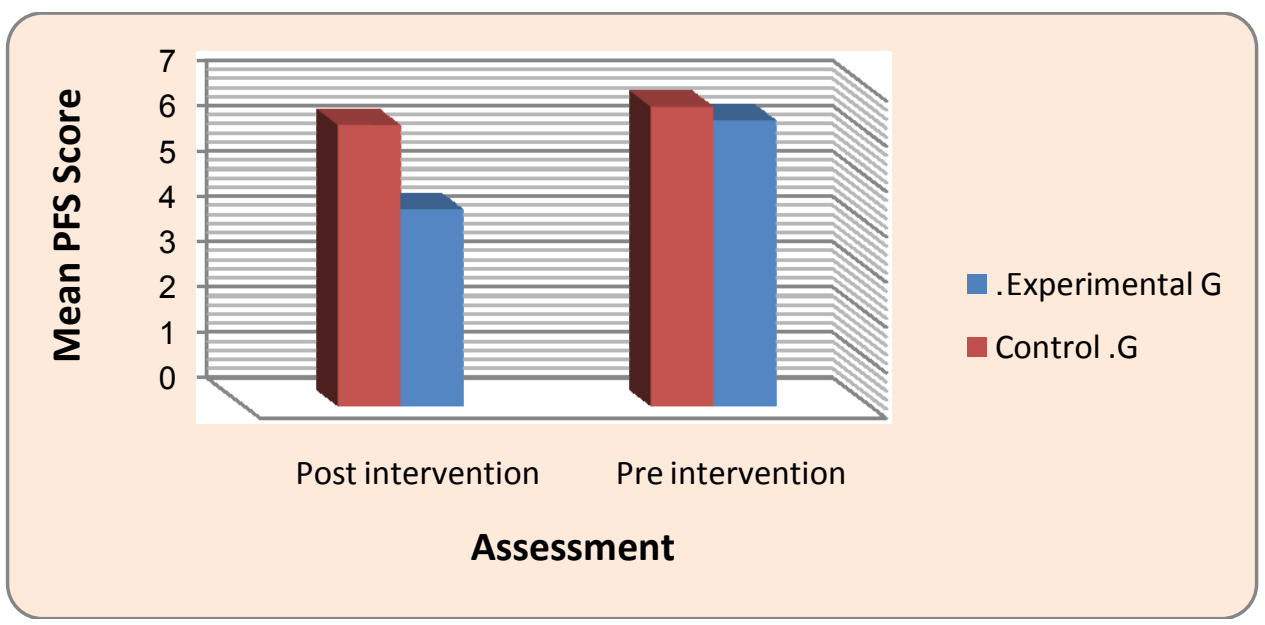

Figure 6.Total mean score of piper fatigue scale at pre intervention and post intervention in both groups

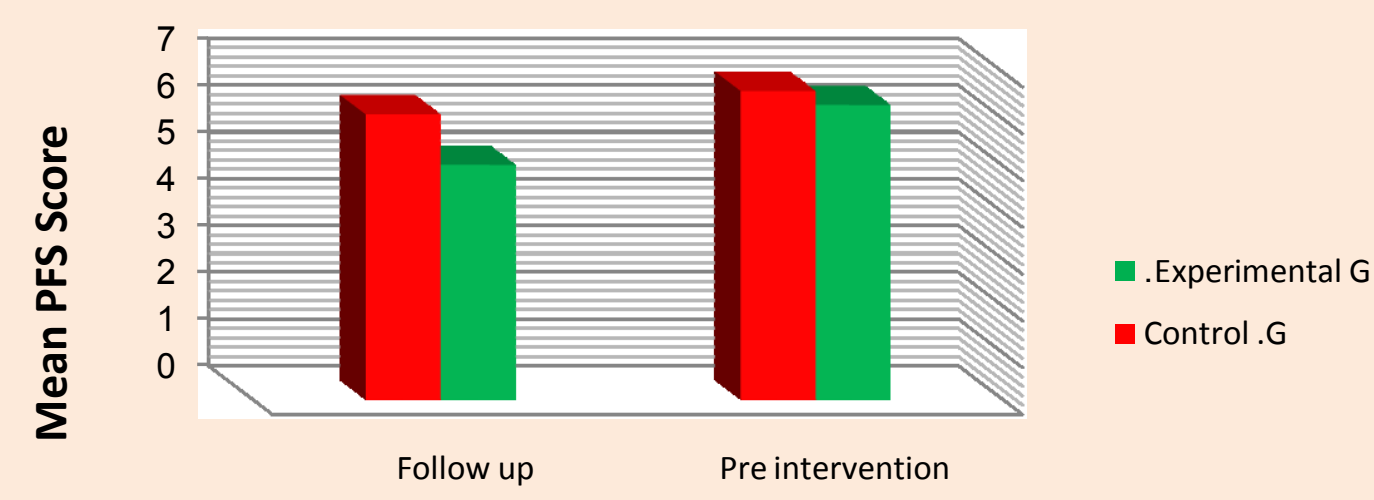

Assessment

Figure 7.Total mean score of piper fatigue scale at post intervention and follow up ( 3 months) in both groups 
The Effectiveness of an Educational Intervention on Fatigue in Hemodialysis Patients: A Randomized

Table 5. Correlation between fatigue score and some variables among experimental group pre, post and follow up program.

\begin{tabular}{|c|c|c|c|}
\hline \multirow[t]{2}{*}{ Some variables } & \multicolumn{3}{|c|}{ Fatigue score } \\
\hline & Pre test & Post test & Follow up \\
\hline \multicolumn{4}{|l|}{ Age } \\
\hline - $\quad r$-value & 0.172 & -0.115 & -0.162 \\
\hline - P-value & $0.05^{*}$ & $0.01 *$ & $0.04 *$ \\
\hline \multicolumn{4}{|l|}{ Gender } \\
\hline - $r$ - value & .239 & .262 & .221 \\
\hline - $\quad$ P-value & .061 & $.01 *$ & $.05^{*}$ \\
\hline \multicolumn{4}{|l|}{ Marital status } \\
\hline - $\quad r$ - value & 0.68 & .158 & .134 \\
\hline - $\quad$ P-value & .212 & .301 & .072 \\
\hline \multicolumn{4}{|l|}{ Education level } \\
\hline - $\quad r$-value & 0.014 & 0.461 & 0.481 \\
\hline - P-value & 0.053 & 0.140 & 0.071 \\
\hline \multicolumn{4}{|l|}{ Frequency of dialysis } \\
\hline - $r$-value & 0.242 & -0.481 & 0.446 \\
\hline - P-value & 0.071 & $0.041 *$ & 0.061 \\
\hline \multicolumn{4}{|c|}{ History of hemodialysis } \\
\hline - $r$-value & 0.264 & 0.282 & 0.453 \\
\hline - P-value & 0.060 & $0.05^{*}$ & $0.01 *$ \\
\hline \multicolumn{4}{|l|}{ Knowledge score } \\
\hline - $r$-value & 0.231 & 0.932 & 0.284 \\
\hline - P-value & 0.06 & $0.01 *$ & $0.032 *$ \\
\hline
\end{tabular}

